\title{
Addictive Behaviour on the Internet: A Quagmire for the Young and Unsuspecting
}

\author{
Trevor Archer*
}

Department of Psychology, University of Gothenburg, Gothenburg, Sweden

The present account examines addictive disorders that are linked to internet technological advances and communicational, more-or-less, unrestricted access, namely gambling disorder, Internet gaming disorder, and most particularly, Internet addiction. Although problems may arise regarding the incidence of so-called 'false-positives' and 'false-negatives' Ferguson, 2018 together complexities pertaining to gender differences and neurogenetic and epigenetic realities that implicate the etioneurogenesis of addiction gaming and internet disorders, it is necessary to apply a perspective of psychobiological and temporary and long-term considerations in order to conceptualize these particular types of addictive behavior [1]. Unsurprisingly it has been postulated that adolescents, generally the main users of novel technologies, apply these new expressions of themselves as vehicles for social interaction. The prevalence of internet addiction may vary considerably between ethnic communities, socioeconomic status and geographic locations. In two cross-sectional Japanese studies, performed over a two-year interval (2014 and 2016) consisting of college students (1,005 participants with a mean age of $18.9 \pm 1.3$ years) the levels of internet addiction, applying Young's Internet Addiction Test, remained more-or-less stable, around the $40-45$ point mark [2]. The propensity for destructive expressions due to the over-exaggerated viewing of gaming aggressiveness and violence, the repeated desensitization to presentations of harmful behavior episodes, incidental criminality and outbursts of impulsive behavior together with anxiety and depression thatare linked to watching violent action video games may climax eventually in the full-fledged abuse of video-internet-smartphone addiction condition [3-5], and mot dangerously in the childhood proclivity for aggressive, out-acting behaviour. However, contrary to the above, it was observed recently that no such influences of violent video-internet gaming were evidenced Kühn, et al. which implies a situation that not uncomplicated. In a cross-sectional study using the Smartphone Addiction Scale, an extremely marked association between smartphone addiction and depression was so highly developed as to constitution an alarming situation [6].

Although Smartphone usage accomplishes a revolutionary manner in which different types of information are acquired, the technology is responsible also for the profound modifications implicated in the teaching of medicine and other disciples. Nevertheless, inadvertent use can negatively affect student learning. Among a Chinese population of young adults (aged 32 years), internet gaming disorder behaviour and addictive symptoms were correlated positively with expressions of stress and correlated negatively with the three factors of positive psychology, namely frustration tolerance, mindfulness, and social support, thereby demonstrating the protective and moderating influence of these factors [7]. Using latent class analysis, smartphone-related problems among 555 Korean middle-school students that related to gaming abuse, Internet use, and smartphone usage patterns were studied [8]. It was observed that gender-related distinctive pattern were displayed among both the male and female students whereby gaming was associated with problematic Internet use in the male participants and aggressiveness and impulsiveness were linked to problematic smartphone usage in the female participants. In a sociodemographic, cross-sectional study of 710 university level students, nearly all the students possessed a smartphone with a total of $96.8 \%$ these adopting usage of this commodity during lectures, classes, and meetings. However, less than half of the students (47.3\%) stated that they used a smartphone for greater than $10 \mathrm{~min}$ for educational purposes, a usage that is higher among clerkship students [9]. At least $95 \%$ of the students reported using a smartphone in the classroom for activities not related to the subject of medicine (i.e. social media and searching for general information) and $68.2 \%$ were considered problematic Internet users according to the internet addiction testing.

Internet addictive behaviours appear to be widespread in several Asian counties including China, Taiwan, Singapore and South Korea as assessed using several diagnostic instruments and frequently presenting co-morbidity with other disorders,

*Corresponding author: Trevor Archer, Department of Psychology, University of Gothenburg, Gothenburg, Sweden

Accepted: June 17, 2019

Published online: June 19, 2019

Citation: Archer T (2019) Addictive Behaviour on the Internet: A Quagmire for the Young and Unsuspecting. Arch Addict Rehabil 2(1):112-114 
such as anxiety and depression, sleep disturbance and Attention Deficit Hyperactive Disorder. For example, among adolescents, risk factors for Internetaddiction may revolve around their own behaviour, familial, and/or parental behaviours. An improved understanding and conceptualization of different aspects of parental behavioural control, parental psychological control, and parent-child relational qualities predicted the initial level and rate of change in adolescent internet addiction as well as the role of teacher and classroom dynamics ought to provide notions pertaining to the extent, severity and handling of internet addictions. In relation to these affective attributes, it was found that the watching of Internet pornographic material exacerbated the risk for internet addiction over time periods whereas factors relating to the classroom, as exemplified by the mean levels of openness-to-experience and introversion, moderated differentially this association the incidence of Internet pornography preference, as an internet addiction risk factor, may be exaggerated within more extroverted classrooms and reduced within openness-to-experience classrooms [10]. Whether or not a continuous construct or a dichotomous construct, it was found that in a large cohort of 956 Chinese adolescents (aged from 11-19 years, $47 \%$ male), it emerged from problematic or non-problematic internet use using Young's Diagnostic Questionnaire that individual, parental, peer, and sociodemographic factors are of necessity to be taken into consideration [11].

Regarding parental control notions, psychological control was associated positively with the initial level of adolescent internet addiction (low level), but increments of maternal psychological control predicted a faster reduction in this addiction [12]. At the outset, it was shown that the behavioural control of both parents was related negatively to the initial level of adolescent expressed internet addiction with only the paternal behavioural control type that presented a significant positive relationship with the rate of linear change in internet addiction which implies that the higher paternal behavioural control predicted a slower decrease in this addiction. Lastly, parent-child relational qualities predicted, negatively and positively, the initial level and the rate of change in internet addiction, respectively. Among Polish secondary school pupils ( $M=16.6, S D=0.77$ ), remarkably, the personality attributes that were most strongly associated with the risky Internet usage included conscientiousness and emotional stability together a demonstrated association between internet addictiveness and applications of coping strategies, involving applications of disengagement, substance use and self-blame [13]; under the conditions of this study it appears that psycho-educational interventions were 'art-and-parcel' of the design and set-up thereby reflecting improvements in attitudes and stress coping strategies. The teacher-pupil relationship forms an important aspect of coping with internet addiction since it was found that Maladaptive Future Time Perspective and hostile treatment of pupils by their teachers were linked to an increase in Problematic Internet Use while, on the other hand, school appreciation was associated with a reduction in Problematic Internet Use and, additionally, hostile treatment by the teachers produced a moderate effect on the maladaptive Future Time Perspective-Problematic Internet Use relationship [14].

The relationship between parental psychological and somatic health and Internet addiction among adolescents presents an avenue of necessary research. In a South Korean cohort of 587 children/adolescents maternal depression was associated with the children's Internet addiction [15], with male children showing higher or normal academic performance and university-educated mothers at highest risk levels. In an evaluation of a large community sample of adolescents ( $N=1105)$, their Internet use/abuse/addiction, the adolescents' attachment to parents and peers, and their psychological profiles were all studied [16]. It was observed that the adolescents' attachment to their parents exerted a marked effect upon their Internet usage and addiction whereby the psychopathological risk involving these individuals exercised a moderating influence upon the relationship between attachment-to-mothers and related Internet usage. In a twelveyear longitudinal study (sample size of $N=142$ adolescents presenting Internet Addiction) to determine whether or not as well as to how emotion-regulation strategies, i.e. those self-focused as opposed to those other-focused, at two years age-periods were related to school-age children's internalizing/externalizing symptoms during the early development emotion regulation strategies among the prevailing expressions internet addiction (compulsive use of the Web versus distressed use) during adolescence [17]. They observed that early emotion regulation dynamics exerted an observable impact upon the emotional-behavioural functioning during middle childhood (i.e. 8 years of age), which in turn wielded an influence upon the onset of internet addiction during adolescence. In a Korean study applying Smartphone Addiction Proneness Scale and the subscales of the Symptom Checklist 90 Items-Revised, with 4854 participants included, internet addiction and smartphone addiction were both associated with an increased risk of depression and anxiety [18]. Internet-addicted individuals expressing chronic, compulsive video game-playing persistence and abuse exhibit an escalating incidence of major depressive disorders and other affective dysfunctional states; these conditions, involving the excessive or problematic game-playing/internet adherence may interact with depression, anxiety and/or several defective, 'out-acting' conditions, clinically, and may magnify the impulsive behaviors associated with internet addiction and video gaming abuse [19]. For instance, the dangers of co-morbidity due to the use and abuse of psychoactive substances and problematic Internet use, gaming, predicted both traditional bullying and cyberbullying victimization among peers [20].

\section{Conclusions}

The prevalence and staging of internet addiction appears to be encroaching upon the biosocio-cognitive development and adjustment of children and adolescents towards sufficient levels of social behaviour, academic performance and well-being. Given that the condition, a so-called impulse control disorder, not involving intoxicating drugs of abuse but bearing similarities to pathological gaming disorders, may im- 
ply certain aspects of the Internet usage allowing individuals to meet, socialize, and exchange ideas, there exist certainly positive advantages accruing from technological benefits. On the other side of the coin, excessive internet use may be to the detriment of 'real life' relationships and those afflicted by Internet addiction may spend more time in solitary seclusion, allocate lesser time with those individuals, "significant-others" important in their lives, and are at risk for being perceived as socially awkward. Finally, the 'volume of time spent on-line' may emanate in familial and social issues, performance deficits and dysregulated life styles.

\section{References}

1. Petry NM, Zajac K, Ginley MK (2018) Behavioral addictions as mental disorders: To Be or Not To Be? Annu Rev Clin Psychol 14: 399-423.

2. Tateno M, Teo AR, Shiraishi M, et al. (2018) The prevalence rate of internet addiction among Japanese college students: Two cross-sectional studies and reconsideration of cut-off points of Young's internet addiction test in Japan. Psychiatry Clin Neurosci 72: 723-730.

3. Archer T, Garcia D, Moradi S (2016) The enigmatic influence of video-internet gaming: Liabilities and assets over the lifespan. Sports Med Rehabil J 1: 1-9.

4. Goldstick JE, Roche JS, Carter PM, et al. (2018) Sex differences in the association between gaming and serious violence among predominantly African American youth. J Interpers Violence 1.

5. Verheijen GP, Burk WJ, Stoltz SEMJ, et al. (2018) Friendly fire: Longitudinal effects of exposure to violent video games on aggressive behavior in adolescent friendship dyads. Aggress Behav 44: 257-267.

6. Alhassan AA, Alqadhib EM, Taha NW, et al. (2018) The relationship between addiction to smartphone usage and depression among adults: A cross sectional study. BMC Psychiatry 18: 148.

7. Yu S, Mao S, Wu AMS (2018) The interplay among stress, frustration tolerance, mindfulness, and social support in internet gaming disorder symptoms among Chinese working adults. Asia Pac Psychiatry 10: e12319.

8. Lee SY, Lee D, Nam CR, et al. (2018) Distinct patterns of internet and smartphone-related problems among adolescents by gender: Latent class analysis. J Behav Addict 7: 454-465.

9. Loredo E Silva MP, de Souza Matos BD, da Silva Ezequiel O, et al. (2018) The use of smartphones in different phases of medical school and its relationship to internet addiction and learning approaches. J Med Syst 42: 106.

10. Alexandraki K, Stavropoulos V, Burleigh TL, et al. (2018) Internet pornography viewing preference as a risk factor for adolescent Internet addiction: The moderating role of classroom personality factors. J Behav Addict 7: 423-432.

11. Zhou N, Cao H, Li X, et al. (2018) Internet addiction, problematic internet use, nonproblematic internet use among Chinese adolescents: Individual, parental, peer, and sociodemographic correlates. Psychol Addict Behav 32: 365-372.

12. Shek DTL, Zhu X, Ma CMS (2018) The influence of parental control and parent-child relational qualities on adolescent internet addiction: A 3-year longitudinal study in Hong Kong. Front Psychol 9: 642.

13. Chwaszcz J, Lelonek-Kuleta B, Wiechetek M, et al. (2018) Personality traits, strategies for coping with stress and the level of internet addiction-a study of polish secondary-school students. Int J Environ Res Public Health 15.

14. Díaz-Aguado MJ, Martín-Babarro J, Falcón L (2018) Problematic Internet use, maladaptive future time perspective and school context. Psicothema 30: 195-200.

15. Choi DW, Chun SY, Lee SA, et al. (2018) The association between parental depression and adolescent's Internet addiction in South Korea. Ann Gen Psychiatry 17: 15.

16. Ballarotto G, Volpi B, Marzilli E, et al. (2018) Adolescent internet abuse: A study on the role of attachment to parents and peers in a large community sample. Biomed Res Int 2018: 5769250.

17. Cimino S, Cerniglia L (2018) A longitudinal study for the empirical validation of an etiopathogenetic model of internet addiction in adolescence based on early emotion regulation. Biomed Res Int 2018: 4038541.

18. Kim YJ, Jang HM, Lee $Y$, et al. (2018) Effects of internet and smartphone addictions on depression and anxiety based on propensity score matching analysis. Int J Environ Res Public Health 15 .

19. Archer T (2018) Internet Gaming Disorder Co-morbidity Linked to Depression and Other Affective Problems. Clin Depress 4: e107.

20. Zsila Á, Orosz G, Király O, et al. (2018) Psychoactive substance use and problematic internet use as predictors of bullying and cyberbullying victimization. Int J Ment Health Addict 16: 466479.

DOI: $10.36959 / 843 / 427$

Copyright: (C) 2019 Archer T. This is an open-access article distributed under the terms of the Creative Commons Attribution License, which permits unrestricted use, distribution, and reproduction in any medium, provided the original author and source are credited. 